Final manuscript Corrosion Science 90 (2015) 1-4

\title{
Direct observation of hydrogen and deuterium in oxide grain boundaries in corroded Zirconium alloys
}

\author{
G. Sundell ${ }^{1}$, M. Thuvander ${ }^{1}$, A.K. Yatim ${ }^{2}$, H. Nordin' ${ }^{3}$, H.-O. Andrén ${ }^{1}$ \\ E-mail: gustav.sundell@chalmers.se \\ Phone: +46-(0)31-772 3291 \\ ${ }^{1}$ Dept. of Applied Physics \\ Chalmers University of Technology \\ 41296 Göteborg, Sweden \\ 2 I. Institute of Physics (IA) \\ RWTH Aachen University \\ 52056 Aachen, Germany \\ ${ }^{3}$ Atomic Energy of Canada Ltd \\ Chalk River Laboratories \\ Chalk River Ontario \\ K0J 1J0 Canada
}

\section{Abstract}

Atom probe tomography has been used to the study the distribution of hydrogen and deuterium in the oxide scale of two common zirconium alloys after autoclave testing in $\mathrm{H}_{2} \mathrm{O}$ and $\mathrm{D}_{2} \mathrm{O}$, respectively. Comparison between hydrogen and deuterium in the mass spectra allows for separation of hydrogen as a corrosion product from adsorbed $\mathrm{H}_{2}$ gas from the vacuum chamber. Enrichment of hydrogen and deuterium, as $\mathrm{OH}^{+}$and $\mathrm{OD}^{+}$, was observed in grain boundaries. The grain boundaries were identified through segregation of iron. This lends experimental support to existing theories for the mechanism of hydrogen pickup in zirconium alloys.

Keywords: A. Atom probe; B. Hydrogen pick-up; C. Zirconium alloys; D. Corrosion; E. Grain boundaries; F. Deuterium

\section{Introduction}

Perhaps the least understood degradation phenomenon of zirconium alloys for nuclear applications is the mechanism of hydrogen pick-up. During waterside corrosion, a fraction of the hydrogen that is released in the water decomposition reaction will be absorbed by the fuel cladding [1] and precipitate as hydrides, eventually leading to embrittlement of the material [2]. Although many studies have been conducted on the subject, no widely accepted mechanism exists that describe how hydrogen penetrates the passive $\mathrm{ZrO}_{2}$ films that are formed on the alloys. Various routes for hydrogen ingress have been proposed, such as interstitial diffusion through the $\mathrm{ZrO}_{2}$ lattice [3], migration through crystallite 
boundaries in the oxide [4], fast transport through secondary phase particles (SPPs) in the oxide scale [5] and $\mathrm{H}_{2} \mathrm{O}$ propagation through microcracks in the passive film [6]. The inherent volatility of hydrogen renders experimental validation of such hypotheses problematic.

Atom probe tomography has some unique virtues for hydrogen detection, such as near-atomic resolution and equal sensitivity to all elements in the periodic table. A major drawback is that substantial amounts of hydrogen from the analysis chamber adsorbs onto the specimen during experiments, obscuring the true hydrogen content in the analyzed material [7]. However, studies have shown that this obstacle may be overcome by using samples exposed to deuterium [8-13]. Deuterium-containing ions in the APT mass spectra shift the peaks by 1 Da with respect to the hydrogen-containing ions that result from the adsorbed gas.

In this study, we use atom probe tomography to compare the hydrogendeuterium distribution in the oxide scale of two common zirconium-based cladding materials - one used in boiling light water reactors (BWR) and another used in CANDU heavy water reactors. Specifically, this allows for spatial mapping of hydroxide/deuterium oxide ions in the spectra that we link to the hydrogen ingress through the passive oxide films.

\section{Materials and experimental details}

The BWR material used in this study is a Zircaloy-2 tube of the Westinghouse designated LK3 ${ }^{\mathrm{TM}}$ heat treatment scheme (see [14] for details). The material is alloyed with $1.32 \% \mathrm{Sn}, 0.17 \% \mathrm{Fe}, 0.10 \% \mathrm{Cr}$ and $0.05 \% \mathrm{Ni}$ (all in wt $\%$ ). The material was corroded in $\mathrm{H}_{2} \mathrm{O}$ in a static steam autoclave at $400^{\circ} \mathrm{C}$ and $10.3 \mathrm{MPa}$ for 15 days, producing an average oxide thickness of $2.3 \mu \mathrm{m}$.

The CANDU material is a $\mathrm{Zr}-2.5 \mathrm{Nb}$ tube that was subjected to $12 \%$ cold drawing after extrusion at $815^{\circ} \mathrm{C}$. The material is alloyed with $2.5 \% \mathrm{Nb}$ and contains $0.114 \% \mathrm{Fe}$ and $0.083 \% \mathrm{C}$ (all in wt\%). The sample was corroded in a heavy water autoclave operated at $335^{\circ} \mathrm{C}$ for 150 days to produce an average oxide thickness of $2.8 \mu \mathrm{m}$. $\mathrm{LiOH}$ was added to the autoclave water, raising the $\mathrm{pH}_{\mathrm{a}}$ to 10.5 .

Needle-shaped atom probe specimens were prepared using a combined focused ion beam and scanning electron microscope workstation (FIB-SEM) in a conventional lift-out procedure followed by a tip-sharpening step with annular milling [15]. The geometry of the tips were such that the direction of the analyses runs normal to the metal-oxide interface, and therefore parallel to the columnar oxide grains that are formed during waterside oxidation of zirconium alloys [16]. The probed volumes in this study are located in the middle of the socalled barrier oxide, approximately $500 \mathrm{~nm}$ away from the metal-oxide interface.

The Zircaloy-2 samples were analyzed in an Imago LEAP 3000X HR atom probe system. Field evaporation is initiated by laser pulsing with green light $(\lambda=532$ $\mathrm{nm}$ ) at a $200 \mathrm{kHz}$ pulse rate, using $0.5 \mathrm{~nJ}$ pulse energy. The temperature of the 
tips was held at $70 \mathrm{~K}$ and the pressure in the chamber was approximately $10^{-9}$ $\mathrm{Pa}$. The Zr-2.5Nb samples were analyzed in a Cameca LEAP 4000X Si system. Field evaporation was in this case initiated by laser pulsing with UV light $(\lambda=$ $355 \mathrm{~nm}$ ) at a $200 \mathrm{kHz}$ pulse rate, using $0.1 \mathrm{~nJ}$ pulse energy. The temperature of the tips was held at $40 \mathrm{~K}$ and the pressure in the chamber was approximately $10^{-}$ ${ }^{9} \mathrm{~Pa}$. APT data was analyzed using the IVAS 3.6.6 software. The reconstructions were made using the default k-factor of 3.3 and an evaporation field of $28 \mathrm{~V} / \mathrm{nm}$.

Results

\section{$\mathrm{H}_{2} \mathrm{O}$-corroded samples}

A number of different peaks in the spectra from the $\mathrm{ZrO}_{2}$ phase can be identified as hydrogen-containing ions, with the most abundant being $\mathrm{H}^{+}, \mathrm{H}_{2}{ }^{+}$and $\mathrm{OH}^{+}$, with small amounts of $\mathrm{H}_{3}{ }^{+}$and $\mathrm{H}_{2} \mathrm{O}^{+}$present. The $\mathrm{H}^{+}, \mathrm{H}_{2}+\mathrm{H}_{3}{ }^{+}$and the $\mathrm{H}_{2} \mathrm{O}^{+}$ions, at 1,2 , 3 and $18 \mathrm{Da}$ respectively, are distributed homogeneously in the 3D reconstructions (see Figure 1). The $\mathrm{OH}^{+}$peak at $17 \mathrm{Da}$, on the other hand, is in some analyses enriched along planar features in the oxide scale. Although APT does not give explicit crystallographic information, we can take advantage of the fact that $\mathrm{Fe}$ is found in oxide crystallite boundaries [17], so that oxide grain boundaries can readily be identified. Interestingly, the $\mathrm{OH}^{+}$peak clearly colocalizes with the $\mathrm{Fe}^{2+}$ peak at $28 \mathrm{Da}$ along grain boundary planes in the oxide scale. There is noticeably a correlation between the $\mathrm{OH}^{+}$ions and the Fe-infused grain boundary in the oxide, and an enrichment of $\mathrm{OH}^{+}$ions in the boundary is evident. However, grain boundaries can be low-field areas of the APT specimen [18], which may attract elevated gas adsorption quantities from the chamber that will field evaporate together with an adjacent oxygen atom. Therefore, the $\mathrm{OH}^{+}$peak in $\mathrm{H}_{2} \mathrm{O}$-corroded samples cannot unequivocally be attributed to hydrogen originating from the corrosion process. Furthermore, additional contribution to the signal from oxygen from the material combining with adsorbed hydrogen species may dilute the apparent localization of the peak.

\section{$\mathrm{D}_{2} \mathrm{O}$-corroded samples}

Similar to the Zircaloy-2 samples, Fe is detected in oxide grain boundaries also in the $\mathrm{Zr}-2.5 \mathrm{Nb}$ alloy, thus enabling identification of boundaries in the oxide also in this material. The $\mathrm{H}^{+}, \mathrm{H}_{2}{ }^{+}$and the $\mathrm{H}_{3}{ }^{+}$are homogenously distributed in the reconstructions (see Figure 2). However, in the beginning of the analysis a focus alignment of the laser beam with respect to the tip was performed. This results in enhanced adsorption of gas from the vacuum, which is reflected in the two horizontal planes with elevated $\mathrm{H}^{+}, \mathrm{H}_{2}{ }^{+}$and $\mathrm{H}_{3}{ }^{+}$levels at the top of the analysis. In the $\mathrm{D}_{2} \mathrm{O}$-corroded materials we can categorically dismiss the entire signal at 1 $\mathrm{Da}$ and $17 \mathrm{Da}$ as adsorbed species from the vacuum chamber, as no $\mathrm{H}$ was present during the autoclave corrosion process. By extension, other hydrogencontaining species that exhibit similar spatial distributions as $\mathrm{H}^{+}$can also be ascribed to gas from the vacuum chamber. Therefore, the elevated 3 Da signal during the laser scan is a strong indication that the peak results from adsorbed $\mathrm{H}_{3}{ }^{+}$species and not a combined $\mathrm{DH}^{+}$ion. 
Strikingly, the peak that is localized to Fe-decorated grain boundaries is now found at $18 \mathrm{Da}$ in the mass spectra of the $\mathrm{D}_{2} \mathrm{O}$-corroded samples. The $\mathrm{OH}^{+}$peak is instead homogeneously distributed in the 3D reconstructions and has no discernable correlation with the grain boundary. As the peak at $18 \mathrm{Da}$ does not co-localize with the $17 \mathrm{Da}$ peak at all, it clearly distinguishes itself from the confirmed adsorbate-containing $\mathrm{OH}^{+}$species. A small peak at $18 \mathrm{Da}$ without spatial localization is found also in the $\mathrm{H}_{2} \mathrm{O}$-corroded material, indicating that the non-localized part of the OD signal is partly adsorbed $\mathrm{H}_{2} \mathrm{O}$ species.

\section{Discussion}

We can for the first time show direct evidence of hydrogen and deuterium enrichment in oxide grain boundaries in autoclave-tested zirconium alloys. This lends experimental support to the hydrogen pick-up mechanism of migration along oxide grain boundaries, which has been proposed by other authors $[4,19]$. It should be noted that although hydrogen and deuterium are detected in the form of $\mathrm{OH}$ or $\mathrm{OD}$, it is not possible to draw any conclusions regarding their chemical or molecular state in the oxide. On the other hand, fourier transformed infrared raman spectroscopy (FTIR) studies by Ramasubramanian et al. have suggested that hydroxyls and hydrogen-bonded water are indeed present in the oxide [4], indicating that this is the chemical environment of the hydrogen in the grain boundaries. As the barrier oxide typically consists of nano-crystalline columnar grains, any random APT analysis will likely capture a number of grain boundaries. Not all APT analyses from the oxide contain hydrogen-enriched boundaries and it is therefore reasonable to assume that only a fraction of these boundaries act as hydrogen transport paths.

These results imply that the texture and the grain boundary chemistry of the oxide must be taken into account when designing zirconium alloys with the view to mitigate hydrogen pick-up. Texture and grain structure of the barrier oxide layer have been identified as important factors for oxidation and hydrogen pickup previously [20,21], and may to some degree be controlled in the processing of cladding tubes. The grain boundary chemistry may influence the electrochemical properties of the oxide scale by moving the cathodic half-cell reaction of the corrosion process away from the metal-oxide interface [22].

\section{Conclusions}

Hydrogen and deuterium are found to be enriched in oxide grain boundaries of autoclave-tested zirconium alloys. Hydrogen originating from the corrosion process can be separated from adsorbed residual $\mathrm{H}_{2}$ gas from the vacuum chamber by comparing mass spectra from $\mathrm{H}_{2} \mathrm{O}$ and $\mathrm{D}_{2} \mathrm{O}$ corroded alloys.

Although the electrochemical state of the detected hydrogen species could not be determined, the results give an indication that oxide grain boundaries are pathways for hydrogen pick-up in zirconium alloys.

\section{Acknowledgements}

The authors would like to thank the MUZIC-2 consortium for helpful discussions. Westinghouse Electric Sweden AB, Sandvik Materials Technology AB, Vattenfall 
$\mathrm{AB}$, the Swedish Research Council and the Deutsch Forschungsgesellschaft (funding within SFB 917) are gratefully acknowledged for their financial support.

\section{References}

[1] S. Kass, J. Electrochem. Soc. 107 (1960) 594-597

[2] C.E. Coleman, D. Hardie, J. Less-Common Metals 11 (1966) 168-85

[3] T. Smith, J. Nucl. Mat. 18 (1966) 323-336

[4] N. Ramasubramanian, V. Perovic, M. Leger, Zirconium in the Nuclear Industry: $12^{\text {th }}$ International Symposium, ASTM STP 1354, 2000, 853-876

[5] Y. Hatano, M. Sugisaki, K. Kitano, M. Hayashi, Zirconium in the Nuclear Industry: $12^{\text {th }}$ International Symposium, ASTM STP 1354, 2000, 901-917

[6] B. Cox, J. Nucl. Mat. 264 (1999) 283-294

[7] G. Sundell, M. Thuvander, H.-O. Andrén, Ultramicroscopy 132 (2013) 285-289

[8] G.L. Kellogg, J.K.G. Panitz, Appl. Phys. Lett. 37 (1980) 625-627

[9] J. A. Spitznagel, S.S. Brenner, M.K. Miller, W.J. Choyke, J. Nucl. Mat. 122-123 (1984) 252-253

[10] Y. Ishikawa, T. Yoshimura, J. Vacuum Soc. Jpn., 41 (1998) 210-212

[11] R. Gemma, T. Al-Kassab, R. Kirchheim, A. Pundt, Scr. Mat. 67 (2012) 903-906

[12] H. Takamizawa, K. Hoshi, Y. Shimizu, F. Yano, K. Inoue, S. Nagata, T. Shikama, Y. Nagai, Appl. Phys. Express 6 (2013)

[13] D. Haley, S.V. Merzlikin, P. Choi, D. Raabe, Int. J. Hydrogen Energy039 (2014) 12221-12229

[14] T. Andersson, T. Thorvaldsson, A. Wilson, A.M. Wardle, Improvements in Water Reactor Fuel Technology and Utilization, IAEA, Vienna, Austria, (1987), 435-449

[15] D.J. Larson, D.T. Ford, A.K. Petford-Long, H. Liew, M.G. Blamire, A. Cerezo, G.D.W. Smith, Ultramicroscopy 79 (1999), 287-293

[16] S. Nanikawa, Y. Etoh, S. Shimada, T. Kubo, K. Ito, H. Harada, Zirconium in the Nuclear Industry: $12^{\text {th }}$ International Symposium, ASTM STP 1354, 2000, 815-835 [17] G. Sundell, M. Thuvander, H.-O. Andrén, Corr. Sci. 65 (2012) 10-12

[18] M. Thuvander, H.-0. Andrén, Mater. Character. 44 (2000) 87-100

[19] M. Lindgren, I. Panas, RSC Adv. 3 (2013) 21613-21619

[20] N. Ni, D. Hudson, J. Wei, P. Wang, S. Lozano-Perez, G.D.W. Smith, J.M. Sykes, S.S. Yardley, K.L. Moore, S. Lyon, R. Cottis, M. Preuss,

C.R.M. Grovenor, Acta Mater. 60 (2012) 7132-7149

[21] K. Une, K. Sakamoto, M. Aomi, J. Matsunaga, Y. Etoh, I. Takagi, S. Miyamura, T. Kobayashi, K. Ito, Zirconium in the Nuclear Industry: $16^{\text {th }}$ International Symposium, ASTM STP 1529, 2012, 401-432

[22] M. Lindgren, I. Panas, G. Sundell, L. Hallstadius M. Thuvander, H.-O. Andrén, Zirconium in the Nuclear Industry 17 th International Symposium, ASTM STP (2013), In Press 
Figures

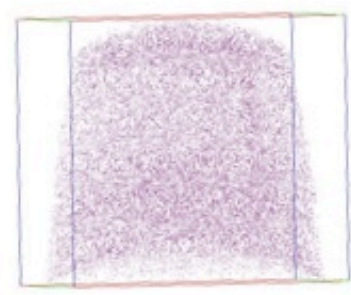

$\mathrm{H}^{+}(1 \mathrm{Da})$

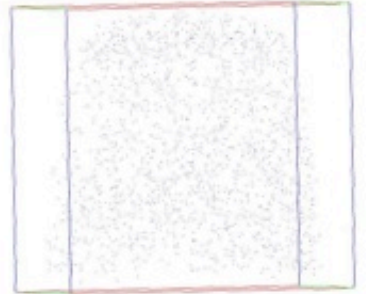

$\mathrm{H}_{3}{ }^{+}(3 \mathrm{Da})$

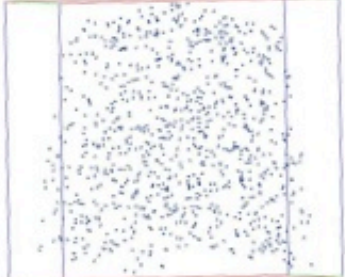

$\mathrm{H}_{2} \mathrm{O}^{+}(18 \mathrm{Da})$

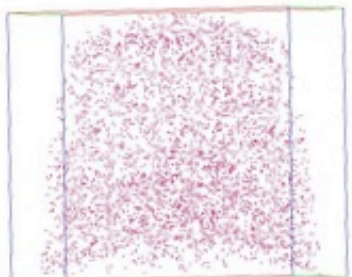

$\mathrm{H}_{2}{ }^{+}(2 \mathrm{Da})$

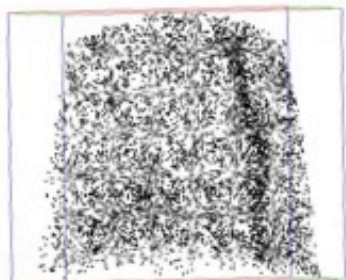

$\mathrm{OH}^{+}(17 \mathrm{Da})$

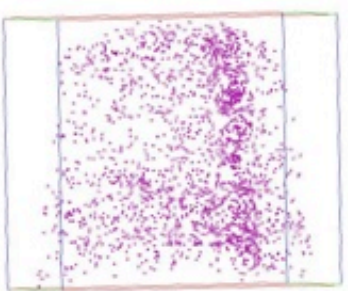

$\mathrm{Fe}^{2+}(28 \mathrm{Da})$

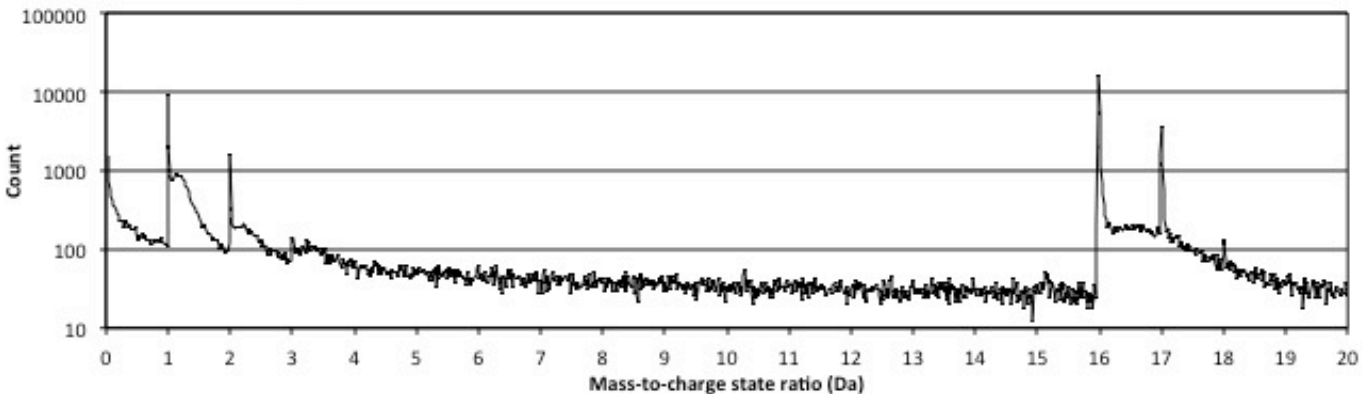

Figure 1: Mass spectrum and 3D reconstructions showing the spatial distribution of the dominant hydrogen-containing peaks from the oxide of Zircaloy-2. Note the enrichment of $\mathrm{OH}$ and Fe along a grain boundary. The size of the boxes in the reconstruction is $70 \times 70 \times 70 \mathbf{n m}^{3}$. 
$\mathrm{H}^{+}(1 \mathrm{Da})$

$\mathrm{H}_{2}^{+} / \mathrm{D}^{+}(2 \mathrm{Da}) \quad \mathrm{H}_{3}^{+} / \mathrm{HD}^{+}(3 \mathrm{Da})$
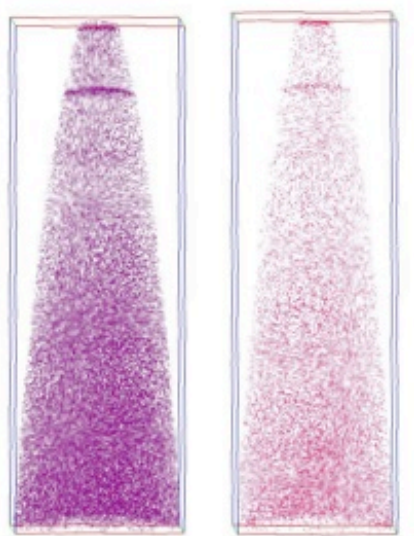

$\mathrm{OH}^{+}(17 \mathrm{Da})$
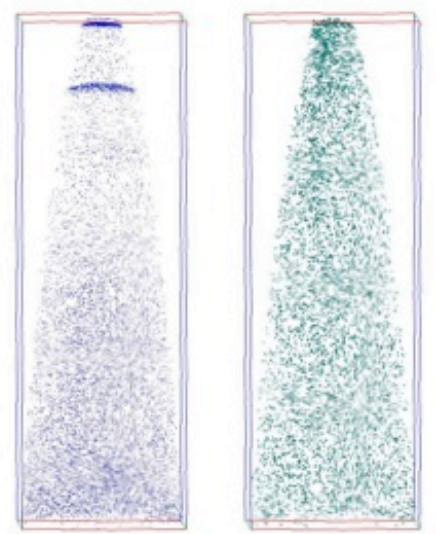

$\mathrm{H}_{2} \mathrm{O}^{+} / \mathrm{OD}^{+}(18 \mathrm{Da})$

$\mathrm{Fe}^{2+}(28 \mathrm{Da})$

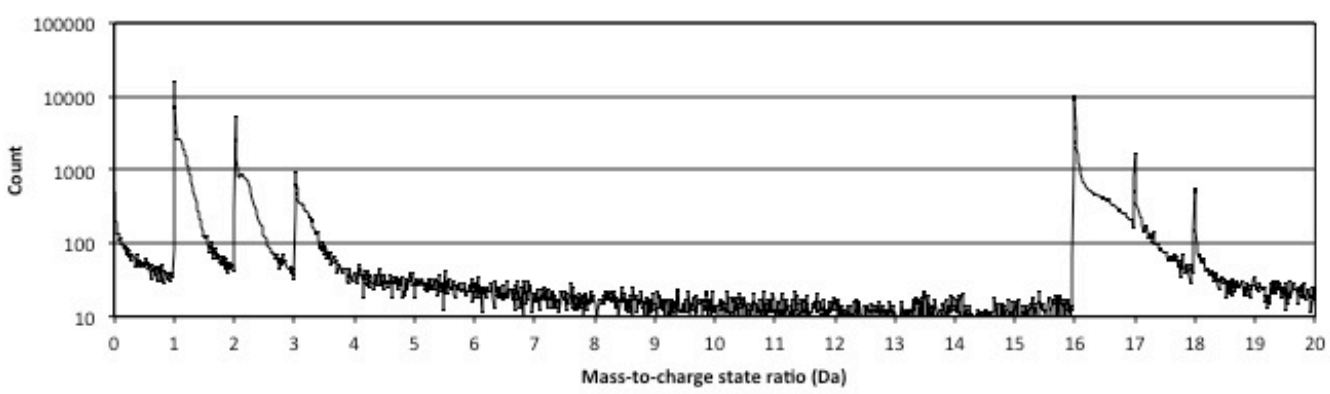

Figure 2: Mass spectrum and 3D reconstructions showing the spatial distribution of the dominant hydrogen-containing peaks from the oxide of $\mathrm{Zr}-2.5 \mathrm{Nb}$. Note the enrichment of $\mathrm{OD}$ and Fe along a grain boundary. The horizontal enrichment of $\mathrm{H}, \mathrm{H}_{2}$ and $\mathrm{H}_{3}$ is adsorbate species resulting from a laser alignment scan. The size of the boxes in the reconstruction is $190 \times 65 \times 65 \mathbf{n m}^{3}$. 